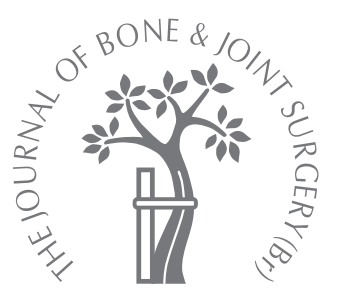

P. Jungbluth, T. M. Frangen, S. Arens, G. Muhr, T. Kälicke

From BG-Kliniken Bergmannsheil Bochum, Bochum, Germany

- P. Jungbluth, MD,

Orthopaedic Surgeon

- T. M. Frangen, MD,

Orthopaedic Surgeon

In S. Arens, MD, Associate

Professor

G. Muhr, MD, Professor

n. Kälicke, MD, Associate

Professor

Department of Surgery

BG-Kliniken Bergmannsheil

Bochum, University of

Bochum, Buerkle-de-la-Camp-

Platz 1, 44789 Bochum,

Germany.

Correspondence should be sent to $\mathrm{Dr}$ T. Kälicke; e-mail pascal.jungbluth@gmx.de

(C)2006 British Editorial Society of Bone and Joint Surgery doi:10.1302/0301-

620X.88B12.17780 $\$ 2.00$

$J$ Bone Joint Surg [Br]

2006;88-B:1629-33.

Received 16 February 2006

Accepted after revision 25 July 2006

\title{
The undiagnosed Essex-Lopresti injury
}

The Essex-Lopresti injury is rare. It consists of fracture of the head of the radius, rupture of the interosseous membrane and disruption of the distal radioulnar joint. The injury is often missed because attention is directed towards the fracture of the head of the radius. We present a series of 12 patients with a mean age of 44.9 years (26 to 54), 11 of whom were treated surgically at a mean of 4.6 months (1 to 16) after injury and the other after 18 years. They were followed up for a mean of 29.2 months ( 2 to 69 ). Ten patients had additional injuries to the forearm or wrist, which made diagnosis more difficult. Replacement of the head of the radius was carried out in ten patients and the Sauve-Kapandji procedure in three. Patients were assessed using standard outcome scores. The mean post-operative Disabilities of the Arm, Shoulder and Hand score was 55 (37 to 83), the mean Morrey Elbow Performance score was 72.2 (39 to 92) and the mean Mayo wrist score was 61.3 (35 to 80). The mean grip strength was $68.5 \%(39.6 \%$ to $91.3 \%)$ of the unaffected wrist.

Most of the patients (10 of 12) were satisfied with their operation and in 11 the pain was relieved. When treating the chronic Essex-Lopresti injury, we recommend accurate realignment of the radius and ulna and replacement of the head of the radius. If this fails a Sauve-Kapandji procedure to arthrodese the distal radioulnar joint should be undertaken to stabilise the forearm while maintaining mobility.

The Essex-Lopresti injury is a rare complex injury of the forearm consisting of a fracture of the head of the radius, rupture of the interosseous membrane and disruption of the distal radioulnar joint. While named after Peter Essex-Lopresti, who reported two cases in $1951,{ }^{1}$ it is generally accepted that the first description dates from 1946 in a paper by Curr and Coe. ${ }^{2}$ It is usually the result of a fall on the outstretched hand. A longitudinal force is transmitted through the wrist to the head of the radius which is fractured. ${ }^{1,3}$ If sufficient force is exerted the head of the radius will dislocate, after which the interosseous membrane ruptures, the distal radioulnar joint is disrupted and the radius migrates proximally leaving the patient with a complex instability of the forearm. ${ }^{4,5}$ The injury is often missed because attention is focused on the fracture of the head of the radius. ${ }^{6}$ The symptoms in the forearm and wrist may be minimal at this stage. Between $0.3 \%$ and $5 \%$ of all fractures of the head are associated with an injury to the interosseous membrane. ${ }^{7}$ After a few weeks the patient experiences ulnocarpal pain in the wrist with restriction of movement due to the relative prominence of the ulna. ${ }^{8,9}$ As the radius shortens, pain and restriction of movement at the elbow increase. While shortening of up to $2 \mathrm{~mm}$ may occur after a simple fracture of the head and be accommodated by intact distal radioulnar ligaments, ${ }^{10,11}$ greater shortening than this strongly suggests an Essex-Lopresti injury. Minor differences in ulnar variance between the injured and uninjured wrists should also be appreciated.

In 1988, Edwards and Jupiter ${ }^{6}$ classified Essex-Lopresti injuries into three types: type I, a fracture of the head with a large displaced fragment and minimal or no comminution which is amenable to open reduction and internal fixation; type II, a comminuted fracture which cannot be reconstructed. Excision of the head with a silastic replacement (Dow Corning, Arlington, Tennessee) is advocated to prevent proximal migration of the shaft of the radius; ${ }^{6}$ type III, chronic cases with irreducible proximal migration of the radius. The two patients in their series were treated by shortening of the ulna because intra-operative traction was unable to restore the length of the radius. ${ }^{6}$

The options for treatment of type-III injuries are limited and controversial. There is no agreed strategy because of the rarity of the 
Table I. Details of 12 patients with an Essex-Lopresti injury

\begin{tabular}{|c|c|c|c|c|c|c|}
\hline Case & Age (yrs) & Gender & $\begin{array}{l}\text { Time to treatment } \\
\text { (mths) }\end{array}$ & Additional injuries & Treatment & $\begin{array}{l}\text { Follow-up } \\
\text { (mths) }\end{array}$ \\
\hline 1 & 32 & $\mathrm{~F}$ & 18 years & Elbow dislocation & $\begin{array}{l}\text { Radial head resection, } \\
\text { Sauve-Kapandji }\end{array}$ & 22 \\
\hline 2 & 50 & $\mathrm{~F}$ & 6 & Elbow dislocation & Sauve-Kapandji & 50 \\
\hline 3 & 43 & M & 1 & $\begin{array}{l}\text { Monteggia fracture, polytrauma } \\
\text { Right acetabular fracture } \\
\text { Left ischial ramus fracture }\end{array}$ & Radial head prosthesis & 57 \\
\hline 4 & 36 & M & 6 & Dislocation of the carpus & Radial head prosthesis & 12 \\
\hline 5 & 49 & $\mathrm{~F}$ & 4 & Monteggia fracture & Radial head prosthesis & 14 \\
\hline 6 & 53 & M & 1 & $\begin{array}{l}\text { Elbow dislocation, comminuted fractured ole- } \\
\text { cranon, } \\
\text { trans-scaphoid fracture-dislocation }\end{array}$ & Radial head prosthesis & 14 \\
\hline 7 & 54 & $\mathrm{~F}$ & 8 & Elbow dislocation & Radial head prosthesis & 36 \\
\hline 8 & 50 & $\mathrm{~F}$ & 1 & $\begin{array}{l}\text { Elbow dislocation, } \\
\text { distal comminuted radial fracture }\end{array}$ & $\begin{array}{l}\text { Radial head prosthesis, } \\
\text { Sauve-Kapandji, } \\
\text { removal of prosthesis }\end{array}$ & 37 \\
\hline 9 & 43 & M & 16 & None & $\begin{array}{l}\text { Radial head resection, } \\
\text { Ulna reduction osteotomy, } \\
\text { Radial head prosthesis, } \\
\text { Change of prosthesis, } \\
\text { Change of prosthesis }\end{array}$ & 2 \\
\hline 10 & 26 & M & 2 & Polytrauma, long-term artificial breathing & Radial head prosthesis & 33 \\
\hline 11 & 49 & M & 5 & Elbow dislocation, dislocation of the carpus & $\begin{array}{l}\text { 1st radial head resection, } \\
\text { 2nd radial head prosthesis }\end{array}$ & 4 \\
\hline 12 & 54 & M & 1 & None & Radial head prosthesis & 69 \\
\hline
\end{tabular}

injury. Since 1951, only 20 cases have been described by seven authors. ${ }^{1,3,7,11-14}$ Our aim was to establish a standard approach to this injury.

\section{Patients and Methods}

Between 1999 and 2005 we treated 12 patients with a previously undiagnosed type-III Essex-Lopresti injury and at least $3 \mathrm{~mm}$ of radial shortening. There were seven men and five women with a mean age of 44.9 years (26 to 54 ). Ten patients had additional injuries to the upper limb, while two had multiple injuries and only two had isolated EssexLopresti lesions (Table I). Surgery was performed at a mean of 4.6 months (1 to 16) after the original injury in 11 patients, and after 18 years in one. The operative management of each patient is shown in Table I. Replacement of the head of the radius was undertaken in ten patients; a monopolar prosthesis (Link, Hamburg, Germany) was used in nine, and a bipolar prosthesis (Tornier, Burscheid, Germany) in one (Fig. 1). One had to be removed because of loosening (case 8) and one was revised twice for loosening (case 9). Three patients underwent a Sauve-Kapandji procedure, including the one whose monopolar prosthesis was removed. The Sauve-Kapandji procedure consists of an arthrodesis of the distal radioulnar joint with the ulnar head being screwed to the base of the distal radius after compensating for the forward movement of the ulna. At the same time, rotation of the forearm is restored by resecting a segment of the ulna of approximately $12 \mathrm{~mm}$ in length. This produces an iatrogenic pseudarthrosis in the region of the ulna. The proximal ulnar segment then assumes the function of a rotating joint. ${ }^{15,16}$

Follow-up was by clinical and radiological examination at a mean of 29.2 months (2 to 69). The function of the upper limb was measured using the Disability of Arm,
Shoulder and Hand (DASH) outcome questionnaire. ${ }^{17}$ On this scale, a score of 0 indicates normal function and 100, maximum disability. The range of movement was measured in the elbow, forearm and wrist. Elbow function was evaluated using the Morrey Elbow Performance Score. ${ }^{18} \mathrm{~A}$ score of 95 to 100 represents an excellent outcome, 80 to 95 good, 50 to 80 average and less than 50, poor. Wrist function was measured using the modified Mayo wrist score. ${ }^{19}$ Scores between 91 and 100 indicate excellent function, 80 to 90 good, 65 to 79 moderate and below 65, poor. The distal radioulnar joint was examined clinically for instability.

Grip strength was measured with a Jamar dynamometer (Fabrication Enterprises Inc., White Plains, New York) using the other hand as a control. After three consecutive bilateral measurements, the grip strength in the injured wrist was expressed as a percentage of the control, allowing a correction factor of 1.07 for the dominant hand over the non-dominant. ${ }^{20}$

Patient satisfaction was determined by questionnaire. Patients were required to state whether they were satisfied with the result of their operation, whether it had reduced pain and improved mobility and whether, in retrospect, they would undergo the same procedure again.

Anteroposterior and lateral radiographs were taken of the injured elbow and forearm, and of both wrists.

\section{Results}

The mean post-operative DASH score was 55 (37 to 83) and the Morrey Elbow Performance score was 72.2 (39 to 92). Elbow flexion was from a mean of $25^{\circ}$ fixed flexion $\left(0^{\circ}\right.$ to $\left.40^{\circ}\right)$, to $117.1^{\circ}\left(90^{\circ}\right.$ to $\left.135^{\circ}\right)$. The mean pronation was $43.3^{\circ}\left(5^{\circ}\right.$ to $\left.90^{\circ}\right)$ and supination was $68.8^{\circ}\left(5^{\circ}\right.$ to $\left.90^{\circ}\right)$. 

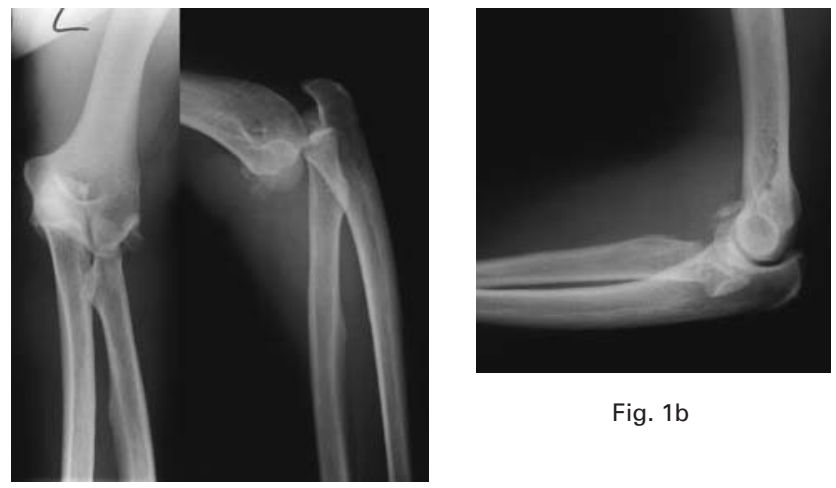

Fig. 1b

Fig. 1a

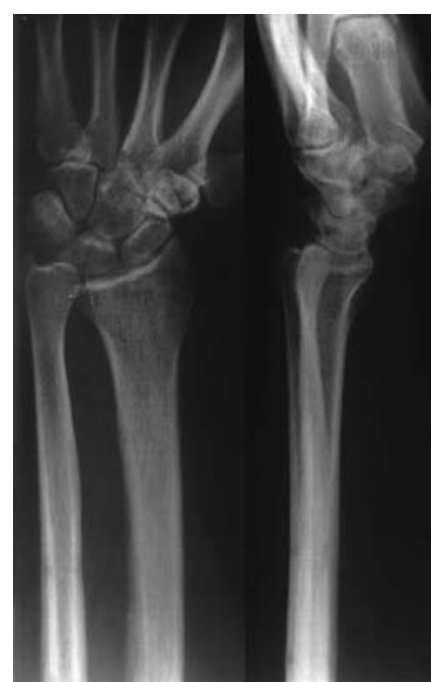

Fig. 1c

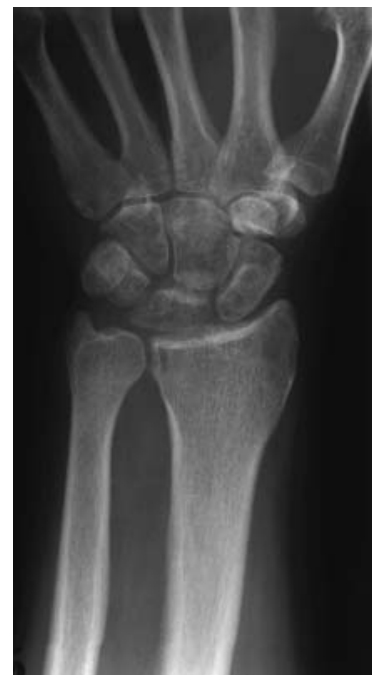

Fig. 1d

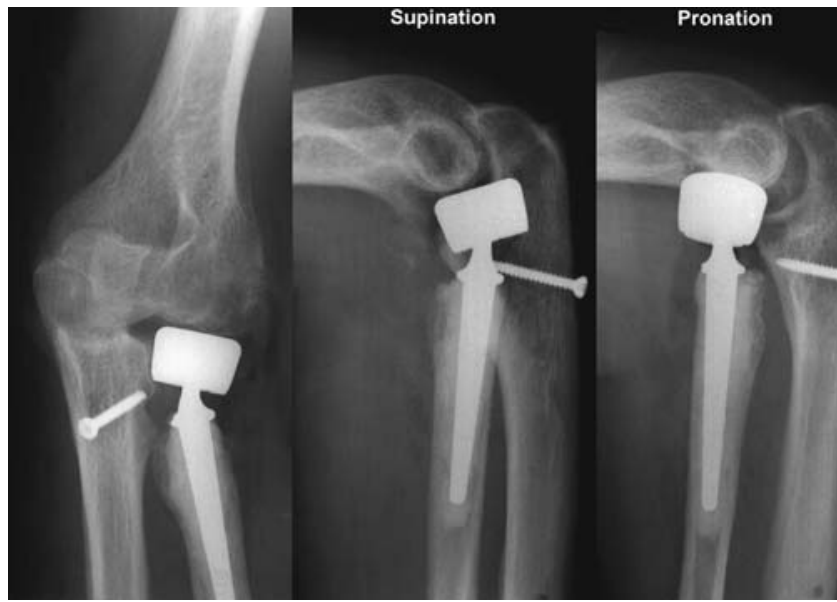

Fig. 1e

Case 11. Radiographs showing a) type III fracture of the radial head combined with dislocation of the elbow, b) after closed reduction, c) proxima migration of the radius, d) and e) radial length was restored after implant-

The mean Mayo wrist score was 61.3 (35 to 80); the mean dorsiflexion was $47.1^{\circ}\left(25^{\circ}\right.$ to $\left.80^{\circ}\right)$ and mean palmar flexion was $47.1^{\circ}\left(30^{\circ}\right.$ to $\left.60^{\circ}\right)$. There were no signs of wrist ing a radial head prosthesis.
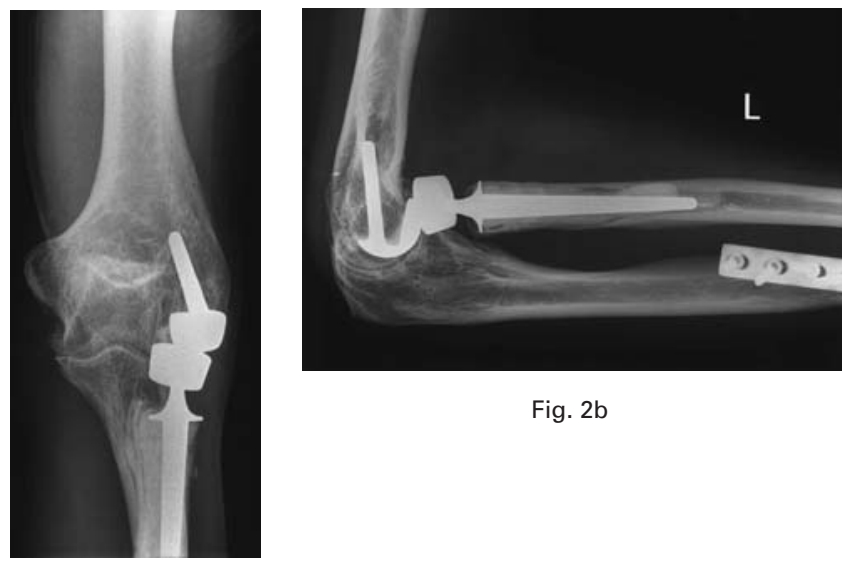

Fig. $2 b$
Fig. 2a

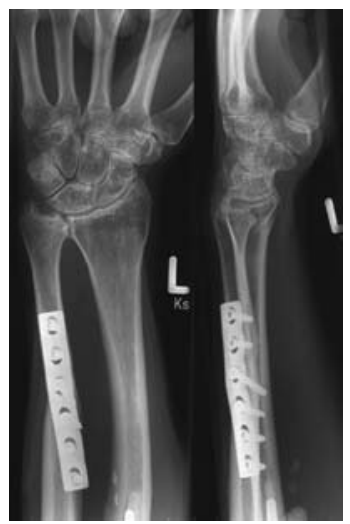

Case 9. Radiographs 56 months after the accident. a) and b) two months after the accident resection of the radial head and an ulna reduction osteotomy were carried out at another clinic. Only a specially designed bipolar prosthesis containing a capitellum shield provided pain relief. c) radial length was restored correctly.
Fig. 2c

instability. The mean pre-operative proximal radial migration was $7.25 \mathrm{~mm}$ (5 to 10), and post-operatively, the value was $0.25 \mathrm{~mm}$ (0 to 11$)$.

The mean grip strength was $68.5 \%$ (39.6\% to $91.3 \%$ ) of the unaffected side when a correction factor of 1.07 was taken into account for dominance.

In four cases we were able to achieve satisfactory or good function simply by replacement of the radial head. These patients also regained excellent grip strength (mean $89.2 \%$ $(87 \%$ to $91.3 \%)$ ) although the patients regarded the relief of pain as more important.

In two cases, the Essex-Lopresti injury was combined with a Monteggia fracture. These patients managed only average or poor function with a weak grip. The presence of a fracture of the shaft of the ulna not only made diagnosis more problematic because of the difficulty in establishing the true relative length of the radius, but also made the operative realignment of the radioulnar joint more difficult to judge.

In two further cases carpal dislocation caused practical difficulties in realigning the distal radioulnar joint.

Ten patients were satisfied with the results of their operation and said that, given the same circumstances, they would undergo the procedure again. Two were not satisfied 


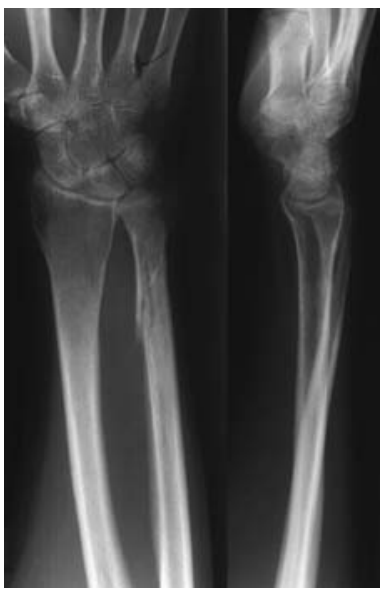

Fig. 3a

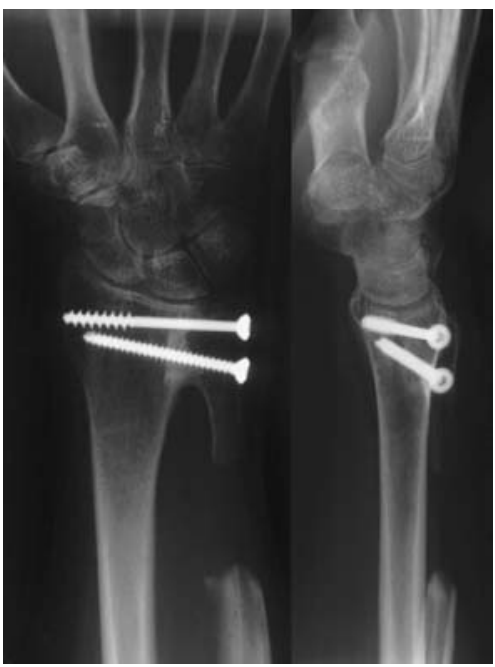

Fig. 3c

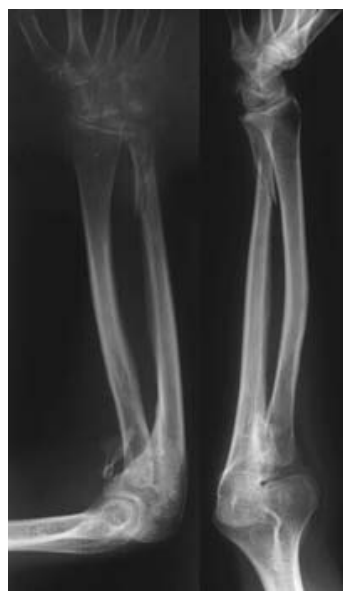

Fig. 3b

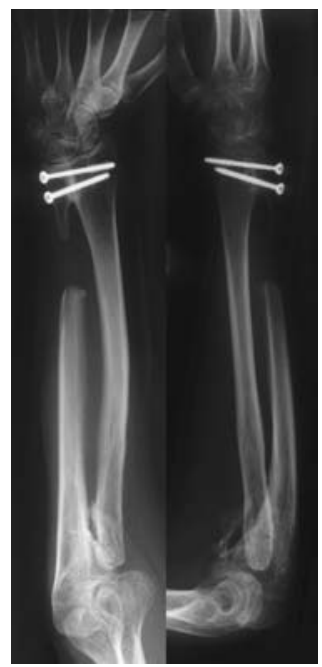

Fig. 3d
Case 1. Radiographs showing a) and b) 18 years after fracture of the radial head. Four years after the accident resection of the radial head was carried out at another clinic and c) and d) after a Sauve-Kapandji procedure (18 years after the initial trauma).

because their mobility did not improve. Pain was reduced in 11, and seven stated that their mobility had improved.

\section{Discussion}

Management of the Essex-Lopresti injury remains a problem because there is no clear strategy for its treatment. The few published cases ${ }^{1,3,7,11-14,21}$ give no clear direction.

We believe that the most important factor is to reestablish the appropriate longitudinal relationship between the radius and the ulna. The proximal and distal radioulnar joints must be fully reduced in order to stabilise the forearm. This may either be achieved by replacement of the head of the radius, which corrects the proximal migration, or by shortening of the distal ulna. ${ }^{3,11-13}$ Resection of the head of the radius alone is inappropriate. ${ }^{3}$
Replacing the head is a demanding operation in these circumstances. The distal radioulnar joint has to be reduced by radial traction and held with a Kirschner wire. Sizing of the implant can also be troublesome, because a prosthesis which is too small will result in instability. In future, it may be possible to use modular prostheses (Fig. 2). The traditional silicon prosthesis is not recommended because of its high rate of complications. ${ }^{12}$ The place of allografts of the head is unclear. In 1997, Szabo et $\mathrm{al}^{13}$ reported success in two cases, but more recently, Karlstad et al ${ }^{12}$ only achieved a satisfactory result in one of four patients.

The Sauve-Kapandji procedure may be useful when the distal radioulnar joint remains unstable, despite the restoration of normal radioulnar alignment. ${ }^{3,7,16}$ We successfully treated three patients using this technique (Fig. 3). All three fused solidly and regained a good grip. Despite reports in the literature to the contrary, ${ }^{22-24}$ there was no osseous bridging of the ulnar defect and no irritation of the ulnar nerve. ${ }^{16}$ Daecke and Martini ${ }^{3}$ and Neuber et $\mathrm{al}^{7}$ have reported similarly good results.

It has been suggested that if instability persists, a radioulnar synostosis (the 'one bone forearm' operation) should be carried out to prevent further radial migration. ${ }^{9}$ This, however, results in complete loss of forearm rotation and is not recommended. ${ }^{25}$ Attempts to reconstruct the interosseous membrane using the palmaris longus tendon remain at an experimental stage. , $^{3,4,26-28}$

Our cases illustrate that the functional outcome of an Essex-Lopresti injury depends on the presence and nature of any associated injury. They also highlight the considerable force required to disrupt the osseous column of the radius and interosseous ligaments. Most reported cases have been associated with similar injuries. ${ }^{1,4,6,7,13,14}$

While we have concentrated on the undiagnosed EssexLopresti injury, we would emphasise the importance of making the correct diagnosis in the acute stage. When there is a displaced fracture of the head of the radius, particularly when this has dislocated, the wrist should be carefully examined for pain, instability and prominence of the ulna, accompanied by pain on pronation and supination of the forearm. If radiographs of both wrists in two planes suggest a proximal shift of the radius of more than $1.9 \mathrm{~mm}$, an Essex-Lopresti injury should be suspected and an MR scan of the whole forearm carried out to identify damage to the interosseous membrane and ulnocarpal ligament complex. ${ }^{10,11}$ The diagnosis may be complicated by the presence of associated injuries.

It is not possible to predict the functional result of an undiagnosed Essex-Lopresti injury in the individual case. However, the residual disability will be minimised if the radius and ulna are realigned and the head of the radius replaced. If this fails to stabilise the forearm, we would recommend the Sauve-Kapandji procedure to arthrodese the distal radioulnar joint.

No benefits in any form have been received or will be received from a commercial party related directly or indirectly to the subject of this article. 


\section{References}

1. Essex-Lopresti P. Fractures of the radial head with radio-ulnar dislocation: report of two cases. J Bone Joint Surg [Br] 1951;33-B:244-7.

2. Curr JF, Coe WA. Dislocation of the inferior radioulnar joint. Br J Surg 1946;34:74-7.

3. Daecke W, Martini AK. Secondary treatment for Essex-Lopresti lesion. Z Orthop 2004;142:235-40.

4. Hotchkiss RN. Injuries to the interosseous ligament of the forearm. Hand Clin 1994;10:391-8.

5. Rabinowitz RS, Light TR, Havey RM, et al. The role of the interosseous membrane and triangular fibrocartilage complex in forearm stability. J Hand Surg 1994;19A:385-93.

6. Edwards GS Jr, Jupiter JB. Radial head fractures with acute distal radioulnar dislocation: Essex-Lopresti revisited. Clin Orthop 1988;234:61-9.

7. Neuber M, Joist A, Joosten U, Rieger H. Consequences and possible treatment of distal radio-ulnar dislocation after Essex-Lopresti lesion. Unfallchirug 2000;103:1093 6 (in German).

8. Friedman SL, Palmer AK. The ulnar impaction syndrome. Hand Clin 1991;72:295310

9. Geel CW, Palmer AK. Radial head fractures and their effect on the distal radioulnar joint: a rationale for treatment. Clin Orthop 1992;275:79-84.

10. Morrey BF, Chao EY, Hui FC. Biomechanical study of the elbow following excision of the radial head. J Bone Joint Surg [Am] 1979;61-A:63-8.

11. Stephen IBM. Excision of the radial head for closed fracture. Acta Orthop Scand 1981;52:409-12.

12. Karlstad R, Morrey BF, Cooney WP. Failure of fresh-frozen radial head allografts in the treatment of Essex-Lopresti injury: a report of four cases. J Bone Joint Surg [Am] 2005;87-A:1828-33.

13. Szabo RM, Hotchkiss RN, Slater RR Jr. The use of frozen-allograft radial head replacement for treatment of established symptomatic proximal translation of the radius: preliminary experience in five cases. J Hand Surg [Am] 1997;22:269-78.

14. van Schoonhoven J, Prommersberger KJ. Differential diagnosis and therapy of post-traumatic limited forearm rotation. Handchir Microchir Plast Chir 2000;32:390-8 (in German).
15. Zilch H, Kauschke T. Kapandji corrective operation of post-traumatic disorder of the distal-ulnar joint. Unfallchirurg 1996;99:841-4 (In German).

16. Kapandji JA. The Kapandji-Sauve operation: its techniques and indications in non rheumatoid diseases. Ann Chir Main 1986;5:181-93.

17. Hudak PL, Amadio PC, Bombardier C. Development of an upper extremity outcome measure: the DASH (disabilities of the arm, shoulder and hand). Am J Ind Med 1996;29:602-8.

18. Morrey BF, An KN, Chao EYS. Functional evaluation of the elbow. In: The elbow and its disorders. Morrey BF, ed. Second ed. Philadelphia: W. B. Saunders, 1993:86-9.

19. Cooney WP, Bussey R, Dobyns JH, Linscheid RL. Difficult wrist fractures: perilunate fracture-dislocation of the wrist. Clin Orthop 1987;214:136-47.

20. Thorngren KG, Werner CO. Normal grip strength. Acta Orthop Scand 1979;50:2559.

21. Trousdale RT, Amadio PC, Cooney WP, Morrey BF. Radio-ulnar dissociation: a review of twenty cases. J Bone Joint Surg [Am] 1992;74-A:1486-97.

22. Haferkamp H. Wrist para-articular radioulnar arthrodeses with distal Kapandji ulnar resection. Handchir Mikrochir Plast Chir 1994;26:313-18 (in German).

23. Pechlaner S, Sailer R. Die arthrodese des distalen radioulnargelenks mit segmentresektion der elle. Operat Orthop Traumato/ 1993;5:48-9.

24. Preisser P, Buck-Gramcko D, Hess J. Distal radio-ulnar arthrodesis and Kapandji ulna segment resection in treatment of limited forearm rotation. Handchir Mikrochir Plast Chir 1991;23:255-61 (in German).

25. Peterson CA 2nd, Maki S, Wood MB. Clinical results of the one-bone forearm. $J$ Hand Surg [Am] 1995;20:609-18.

26. Skahen JR, Palmer AK, Werner FW, Fortino MD. The interosseous membrane of the forearm: anatomy and function. J Hand Surg [Am] 1997;22:981-5.

27. Sowa DT, Hotchkiss RN, Weiland AJ. Symptomatic proximal translation of the radius following radial head resection. Clin Orthop 1995;317:106-13.

28. Tomaino MM, Pfaeffle J, Stabile K, Li ZM. Reconstruction of the interosseous ligament of the forearm reduces load on the radial head in cadavers. $J$ Hand Surg $[B r]$ 2003;28:267-70 